\title{
Water Requirement and Deficit Irrigation of Capsicum Crop using Fixed Irrigation Intervals to Crop Stage under Poly House
}

\author{
J. Trivikrama Raju ${ }^{1} *$, G. Muralee Krishna ${ }^{2}$, H.V. Hema Kumar ${ }^{3}$ and P. Sumathi ${ }^{4}$ \\ ${ }^{1}$ Department of SWE, College of Agricultural Engineering, Bapatla, 522101, India \\ ${ }^{2}$ College of Agricultural Engineering, Madakasira, 515301, India \\ ${ }^{3}$ Department of Soil and Water Conservation Engineering, CAE, Bapatla-522101, India \\ ${ }^{4}$ Department of Statistics and Mathematics, CAE, Madkasira, India
}

*Corresponding author

\begin{abstract}
A B S T R A C T
\section{Keywords}

Water requirement,

Deficit irrigation,

Capsicum, Fixed

irrigation interval,

Article Info

Accepted:

17 June 2018

Available Online:

10 July 2018

This study was conducted in order to determine effect of water requirement, irrigation treatments and water use efficiency of capsicum crop. Experiments were carried out in the College of Agricultural Engineering, Madakasira between January to May 2018, with cv. Indra. The maximum yield of $4.3 \mathrm{t}$ $\mathrm{ha}^{-1}$ was obtained from treatment $1\left(1.0 \mathrm{ET}_{\mathrm{c}}\right)$. The seasonal irrigation water amount of treatment was $562.5 \mathrm{~mm}$ determined by AquaCrop 6.0 model. Capsicum yield of $3.8 \mathrm{t} \mathrm{ha}^{-1}$ was obtained under treatment $2\left(0.75 \mathrm{ET}_{\mathrm{C}}\right)$ of $421.87 \mathrm{~mm}$ seasonal irrigation water requirement and under treatment 3 $\left(0.5 \mathrm{ET}_{\mathrm{C}}\right) 2.1 \mathrm{t} \mathrm{ha}^{-1}$ with the seasonal irrigation water amount of $281.25 \mathrm{~mm}$. Although water saving of $140.63 \mathrm{~mm}$ in treatment 2 and $281.25 \mathrm{~mm}$ in treatment 3. The method of determination of water requirement is AquaCrop 6.0 model. Predicted water requirement through AquaCrop is compared with the pan evaporation data. From this experiment AquaCrop model appeared to be most reasonable and effective one in terms of yield and WUE. On the other hand, the maximum irrigation water use efficiency $9.19 \mathrm{~kg} \mathrm{ha}^{-1} \mathrm{~mm}^{-1}$ in treatment 2 followed by treatment 1 and treatment 3 .

\section{Introduction}

India is the second largest producer of vegetable crops in the world. However, its vegetable production is much less than the requirement if balanced diet is provided to every individual. There are different ways and means to achieve this target, example, bringing additional area under vegetable crops using hybrid seeds, use of improved agrotechniques. Another potential approach is perfection and promotion of protected cultivation of vegetables. In hilly areas parts of the country especially in southern India the

soils are highly fertile but extremes of temperature ranging from $0{ }^{\circ} \mathrm{C}-48^{\circ} \mathrm{C}$ during the year do not allow year round outdoor vegetable cultivation. Some of the areas are inaccessible as well as inhospitable where normal cultivation is not possible. To provide people with food and drink at a social event or other gathering in the inaccessible areas greenhouse cultivation could be an answer. There is very good and sustainable demand for fresh vegetables around the cities and towns. The main purpose of protected cultivation is to create a favourable environment for the sustained growth of crop so as to realize its
\end{abstract}


maximum potential even in adverse climatic conditions.

Protected Cultivation technology is a relatively new technology in India. The total area covered under protected cultivation in India is approx. 30,000 hectares (Shweta et al., 2014). The leading states in the area of protected cultivation are Maharashtra, Karnataka, Himachal Pradesh, and Northeastern states, Uttarakhand, Tamilnadu and Punjab. The major crops grown in the protected cultivation are tomato, capsicum, cucumber, melons and rose etc. Nursery grown in the protected cultivation is becoming very popular venture for income and employment generation.

Bell peppers are belonging to the species Capsicum annuum. Cultivars of these plants produce fruits in many different colours and shapes. Usually the colours range from red to yellow and orange, but more exotic colours include purple, white and lime green. The fruit is also frequently consumed in its unripe form, when the fruit is still green.

At present throughout the world approximately $80 \%$ of the fresh water is used for agriculture and food production. Agriculture is the primary economic activity in many countries. However, the amount of water available for irrigation is consistently declining as a result of pressure from other competing demands (domestic, recreation and industrial uses). The main reasons for degradation of agricultural land are excess water application in irrigation. Huge areas of land become unusable for agriculture due to the rise of water tables and high concentrations of salts in the soil profile as a result of inappropriate irrigation. Rapid spread of diseases that infect human beings such as malaria and fever, as well as environmental degradation are the likely result of poorly planned and implemented irrigation projects. This calls for optimization of irrigation project planning and optimum use of the water available for irrigation. Generally, optimization of irrigation water management is necessary for structural (irrigation system design), economic (saving water and energy), and environmental reasons (salt accumulation in soil surface and agro-chemicals leaching into ground water).

Irrigation improves yield, not only by direct effect on mitigating water stress, but also by encouraging farmers to invest in inputs like fertilizers and improved cultivars, in which they are otherwise reluctant to invest due to uncertainty of crop production under rainfed conditions. Irrigation can also prolong the effective crop-growing period in areas with extended dry seasons, thus permitting multiple cropping per year where only a single crop would otherwise be possible.

Crop water requirements can also be determined by monitoring atmospheric conditions. Pan evaporation, which incorporates the climatic factors that influence evapotranspiration into a single measurement, has been used to schedule irrigation for several crops. An FAO crop factor approach can be utilized to calculate water requirements and schedule irrigation of crops.

In this study, we used AquaCrop model to determine water requirement. Effect on yield, water use efficiency was measured for different irrigation treatments for capsicum.

\section{Materials and Methods}

\section{Study area}

Madakasira was located in Anantapuram district of Andhra Pradesh, nearest to Karnataka state border. Madakasira is bounded by Pavagada in North, Neelakantapuram in South, Dommathmarri of Karnataka village in east and Amarapuram in west. It is located in arid ecological zone, 
mainly it is designated as rain shadow region . The area has Latitude of $13^{\circ} 94^{\prime} 56.89^{\prime \prime} \mathrm{N}$ and longitude of $77^{\circ} 18^{\prime} 42^{\prime} \mathrm{E}$.

\section{Weather during crop period}

During the crop period of capsicum, a total amount of $86.3 \mathrm{~mm}$ rainfall was received in 10 rainy days. The mean sea level is 646 meters. The annual rainfall of Madakasira is 608.55 $\mathrm{mm}$, having wind velocity up to $13.57 \mathrm{Kmph}$ and it is found to be draught prone area. The mean maximum temperature is about $34.05^{\circ} \mathrm{C}$ and means minimum temperature is $23.21^{\circ} \mathrm{C}$ was observed. In Madakasira the predominant soils are silty loam soils. The majorly grown crop is Groundnut. It is majorly suffering due to the major shall requirement for drinking water with high concentrations of fluoride.

\section{Soil}

The soil of the experimental plot was tested for its suitability and nutrient content at Agricultural Research Station, Rekulakunta, Anantapur. The details of the soil report presented in Table 1.

\section{Irrigation water}

The irrigation water for cultivation of capsicum crop was taken from bore existed at College of Agricultural Engineering, Madakasira. It is tested and presented in the following table 2 .

\section{Crop details}

The seedlings were brought from the nursery and seedlings age is 45 days. The crop variety was Indra which is turn from full green changes to red with 140 to 150 days of crop duration. The spacing is plant to plant is $40 \mathrm{~cm}$ and row to row spacing is $50 \mathrm{~cm}$. The experiment was laid out using Complete Randomized Design with five replications. Different levels of irrigation water with three treatments were set in the experimental field. The layout plan is depicted in Figure 1.

\section{Drip irrigation system}

Drip irrigation system was installed in the experimental plots, Madakasira and it consists of a head control unit, water carrying unit and water distribution unit. The head control unit consist of non-return valve 30 litre fertilizer tank, pressure gauge. The layout of the drip irrigation system: Water was pumped through $10 \mathrm{hp}$ motor through water meter measuring the quantity of water. The layout consists of $40 \mathrm{~mm}$ mains and sub mains. The water source for irrigation was from a bore well. There are thirty raised beds in the experimental field. Each bed has $4 \mathrm{~m}$ length and $0.9 \mathrm{~m}$ width and two laterals fitted with micro valve to operate the particular lateral. The laterals of $16 \mathrm{~mm}$ diameter were laid at $0.5 \mathrm{~m}$ apart with spacing of $0.4 \mathrm{~m}$ distance between two inline emitters. The emitter discharge was $3.9 \mathrm{lph}$. Control valves were fixed separately to each treatment plot to facilitate controlling the water flow as per the treatments in the experiment.

\section{Determination of water requirement}

In present study the calculation of irrigation water requirement is done by using AquaCrop 6.0 model developed by FAO. Standard procedure was followed to calculate the crop water requirement for 21 years of weather data.

\section{Yield and water use efficiency}

From the selected plants we observed number of Number of fruits per plant, Length of fresh fruit, Average fruit weight, Number of fruits / plant, number of pickings and Yield $\mathrm{kg} / \mathrm{ha}$ were recorded as yield parameters. 
Table.1 Pre-cropping soil sample analysis report of the experimental plot

\begin{tabular}{|c|c|c|c|}
\hline S.No. & Soil Characteristic & Value & Indication \\
\hline $\mathbf{1}$ & $\mathrm{pH}$ & 9.4 & Sodic \\
\hline $\mathbf{2}$ & $\mathrm{EC}$ & $0.88 \mathrm{dS} / \mathrm{m}$ & - \\
\hline $\mathbf{3}$ & Organic Carbon & $0.54 \%$ & Medium \\
\hline $\mathbf{4}$ & Nitrogen & $176 \mathrm{~kg} / \mathrm{ha}$ & Less \\
\hline $\mathbf{5}$ & Potassium & $325 \mathrm{~kg} / \mathrm{ha}$ & More \\
\hline $\mathbf{6}$ & Phosphorous & $32 \mathrm{~kg} / \mathrm{ha}$ & Medium \\
\hline
\end{tabular}

Table.2 Water analysis report irrigation water used for cultivation of capsicum crop

\begin{tabular}{|c|c|c|}
\hline S.NO & Parameter & values \\
\hline $\mathbf{1}$ & $\mathrm{pH}$ & 7.21 \\
\hline $\mathbf{2}$ & $\mathrm{EC}$ & $1368 \mu \mathrm{s} / \mathrm{cm}$ \\
\hline $\mathbf{3}$ & TDS & $882.5 \mathrm{mg} / \mathrm{lit}$ \\
\hline $\mathbf{4}$ & Total hardness & $332 \mathrm{mg} / \mathrm{lit}$ \\
\hline $\mathbf{5}$ & Total alkalinity & $600 \mathrm{mg} / \mathrm{lit}$ \\
\hline $\mathbf{6}$ & Fluoride & $1.8 \mathrm{mg} / \mathrm{lit}$ \\
\hline $\mathbf{7}$ & Sulphate & $34 \mathrm{mg} / \mathrm{lit}$ \\
\hline $\mathbf{8}$ & Nitrate & $37.57 \mathrm{mg} / \mathrm{lit}$ \\
\hline $\mathbf{9}$ & Iron & $0.01 \mathrm{mg} / \mathrm{lit}$ \\
\hline $\mathbf{1 0}$ & Chloride & $184 \mathrm{mg} / \mathrm{lit}$ \\
\hline
\end{tabular}

Table.3 Yield of capsicum in different treatments

\begin{tabular}{|c|c|c|}
\hline Treatment & Yield per plot kg & Yield kg/ha \\
\hline T1 & 27.9 & 4359.38 \\
\hline T2 & 24.8 & 3875.00 \\
\hline T3 & 13.5 & 2109.38 \\
\hline Open & 2.8 & 437.50 \\
\hline
\end{tabular}

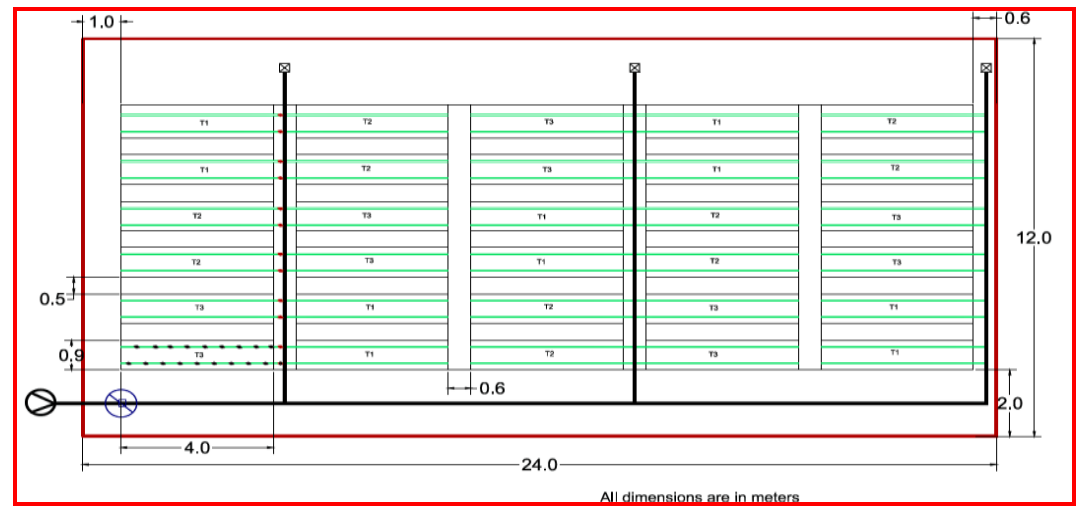




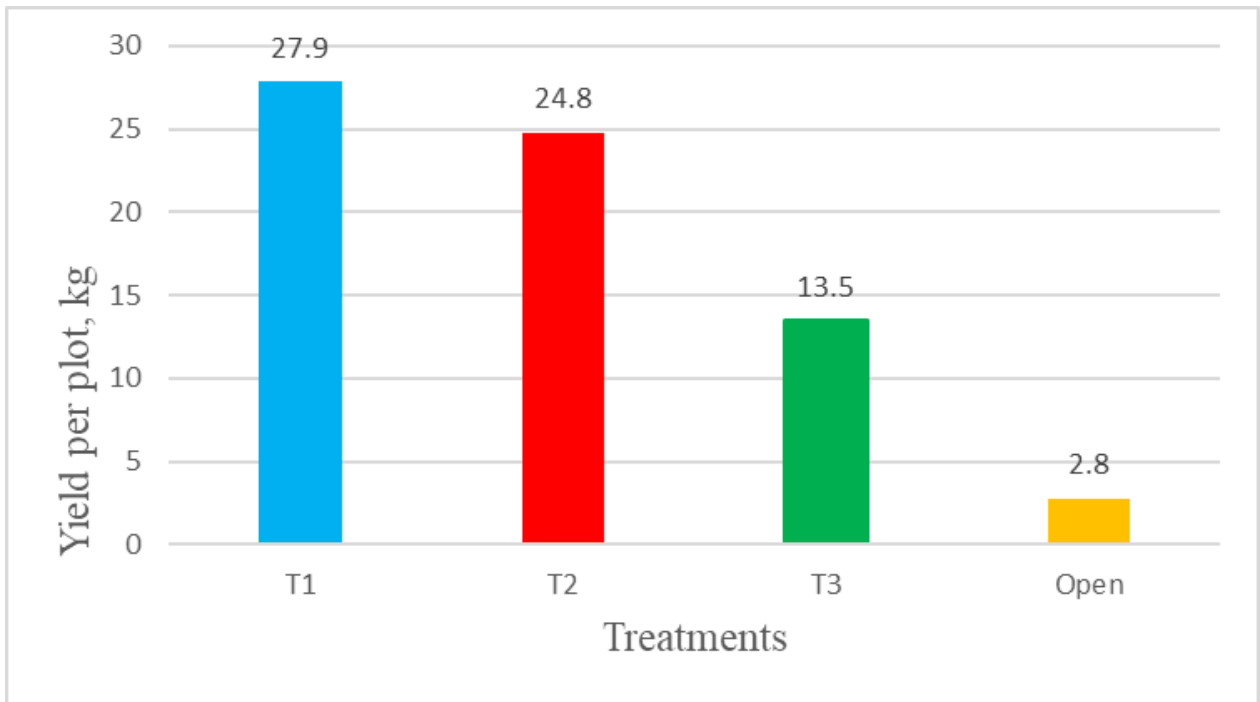

Yield of the total fruits of the capsicum harvested in different pickings from the sample plants in each treatment was recorded and averages were worked out and it was calculated for hectare.

Water use efficiency of the capsicum crop for different irrigation levels Total water used in each irrigation treatment was calculated by using following formula and expressed as $\mathrm{mm}$.

Total water used $(\mathrm{mm})=$ water applied at all irrigations $(\mathrm{mm})+$ rainfall $(\mathrm{mm})$.

Water use efficiency (WUE) is the ratio between seed yield to the amount of water used. It was worked out by using the following formula and expressed as $\mathrm{kg} \mathrm{ha}^{-1}$ $\mathrm{mm}^{-1}$.

WUE = yield obtained $(\mathrm{kg}) /$ water applied --- (3.2)

Daily evaporation $(\mathrm{mm})$ for the growing season was recorded from the USWB Class A pan evaporimeter situated at the College of Agricultural Engineering, Madakasira (Appendix). The cumulative daily evaporation during crop growth period was $996 \mathrm{~mm}$.

\section{Results and Discussion}

The total yield of each plot and productivity were presented in Table 3. The highest yield was recorded in $\mathrm{T} 1$ as $27.9 \mathrm{~kg}$ followed by T2 as $24.8 \mathrm{~kg}$, T3 as $13.5 \mathrm{~kg}$ and open field as 2.8 $\mathrm{kg}$. The results are in agreement with Pardon et al. (2015) in bell pepper and Rao et al., (2013) for Capsicum crop.

Lowest yield was observed in open field. This is shown in Figure 1 and is also presented in Table 3.

In conclusions, the highest yield was recorded in $\mathrm{T} 1$ as $27.9 \mathrm{~kg}$ followed by $\mathrm{T} 2$ as $24.8 \mathrm{~kg}$, T3 as $13.5 \mathrm{~kg}$ and open field as $2.8 \mathrm{~kg}$. The total water consumed was281.55, 421.87, 562.5 and $681.55 \mathrm{~mm}$ in the poly house with drip irrigation in $0.5,0.75,1.0 \mathrm{ET}_{\mathrm{C}}$ and 1.0 $\mathrm{ET}_{\mathrm{C}}$ in open field, respectively. The water use efficiency is the drip irrigation scheduled at 0.75 ET $_{\mathrm{C}}$ recorded maximum water productivity $\left(9.19 \mathrm{~kg} \mathrm{ha}^{-1} \mathrm{~mm}^{-1}\right)$ followed by drip irrigation scheduled at $1.0 \mathrm{ET}_{\mathrm{C}}(7.75 \mathrm{~kg}$ $\left.\mathrm{ha}^{-1} \mathrm{~mm}^{-1}\right), 0.5 \operatorname{ET}_{\mathrm{C}}\left(7.50 \mathrm{~kg} \mathrm{ha}^{-1} \mathrm{~mm}^{-1}\right)$ and open field $\left(0.64 \mathrm{~kg} \mathrm{ha}^{-1} \mathrm{~mm}^{-1}\right)$ recorded very less. From this we can conclude that $0.75 \mathrm{ET}_{\mathrm{c}}$ is the best treatment over other all treatment. 


\section{References}

Cakir, R., Cebi, U.K, Altintas, S and Ozdemir, A. 2017. Irrigation scheduling and water use efficiency of cucumber grown as a spring-summer cycle crop in solar greenhouse. Agricultural Water Management. 180: 78-87.

Gupta, A.J., Ahmad, M.F and. Bhat, F.N. 2010. Studies on yield, quality, water and fertilizer use efficiency of capsicum under drip irrigation and fertigation. Indian Journal of Horticulture. 67(2): 213-218.

Ismail, S.M. 2010. Influence of deficit irrigation on water use efficiency and bird pepper production (Capsicum annuит L.). Environmental \& Arid Land Agricultural Science. 21(2): 2943.

Lodhi, A.S., Kaushal, A and Singh, K.G. 2014. Impact of irrigation regimes on growth, yield and water use efficiency of sweet pepper. Indian Journal of Science and Technology. 7(6): 790794.

Montoya, F., Camargo, D., Ortega, J.F., Corcoles, J.I. and Dominguez, A.
2015. Evaluation of Aquacrop model for a potato crop under different irrigation conditions. Agricultural water Management. 1-14.

Ocharo, N.E., Joseph, P.G and Nicholas, K.K. 2017. Plant row spacing effect on growth and yield of green pepper (Capsicum annuиm L.) in western Kenya. Archives of Current Research International. 7(3): 1-9.

Padron, R.A.R., Guedes, J.V.C., Swarowsky, A., Nogueira, C.U., Cerquera, R.R and Perez, J.C.D. 2015. Supplemental irrigation levels in bell pepper under shade mesh and in open-field: Crop coefficient, yield, fruit quality and water productivity. African Journal of Agricultural Research. 10(44): 41174125.

Rao, K.V.R., Agrawal, V., Chourasia, L., Keshri, R and Patel, G.P. 2013. Performance evaluation of capsicum crop in open field and under covered cultivation. International Journal of Agricultural Sciences. 9(2): 602-604.

Shweta, Bhatia, S.K and Malik, M. 2014. Protected farming. Popular Khethi. 2(1): 74-79.

\section{How to cite this article:}

Trivikrama, J. Raju, G. Muralee Krishna, H.V. Hema Kumar and Sumathi, P. 2018. Water Requirement and Deficit Irrigation of Capsicum Crop using Fixed Irrigation Intervals to Crop Stage under Poly House Int.J.Curr.Microbiol.App.Sci. 7(07): 2533-2538. doi: https://doi.org/10.20546/ijcmas.2018.707.297 